\title{
The causes of Spanish unemployment: A structural VAR approach ${ }^{1}$
}

\author{
Juan J. Dolado a, Juan F. Jimeno ${ }^{\text {b, * }}$ \\ a Department of Economics, Universidad Carlos III, Madrid 126, 28903 Getafe, Madrid, Spain \\ ${ }^{b}$ Universidad de Alcalá de Henares and FEDEA, Jorge Juan 46, 28001 Madrid, Spain
}

Received 1 May 1995; accepted 1 November 1996

\begin{abstract}
In this paper, we review the main causes of Spanish unemployment and weight them by estimating a simple macroeconomic model using the structural VAR methodology. By using this methodology we associate different causes of unemployment with shocks of different nature which have long-lasting effects due to full hysteresis. We claim that such an extreme assumption on 'state dependency' is reasonable, at least as a local approximation, for the period and the economy at hand. Our results suggest that the combination of a plausible mixture of different types of shock and extreme persistence in their propagation mechanisms can satisfactorily explain the dismal performance of the Spanish labour market during the last two decades. (C) 1997 Elsevier Science B.V.
\end{abstract}

JEL classification: $\mathrm{J} 60 ; \mathrm{E} 24$

Keywords: Unemployment; Hysteresis; Structural VAR

\footnotetext{
* Corresponding author.

${ }^{1}$ This paper was started in 1995, when the first author was visiting CEMFI, and a preliminary version was circulated under the title "Why is Spanish unemployment so high?". We are grateful to S. Castillo and R. Duce for excellent research assistance, and to S. Bentolila, P. Burridge, D. López-Salido, R. Marimón, A. Oswald and two anonymous referees for their comments and suggestions. We also thank participants in seminars at the Bank of Portugal, ECARE, European University Institule of Florence, University of Munich, University Carlos III (Madrid), and the 1995 Royal Economic Society Conference, for helpful comments. J.F.J. acknowledges financial support from the Spanish Ministry of Education through a DGICYT grant (project SEC 95-0131). The usual disclaimer applies.
} 


\section{Introduction}

No country in the OECD has as great an unemployment problem as Spain. The Spanish unemployment rate is the highest and most stubborn: it rose dramatically during the second half of the 1970s and the first half of the 1980s (from 5\% to $21 \%$ ) and, after a brief drop in the second half of the 1980 s (from $21 \%$ to $16 \%$ ), resumed an upward trend at the beginning of the 1990 s (from $16 \%$ to $24 \%$ ). Only recently are there some signs of a pause in this unfavourable evolution. As shown in the top panel of Fig. 1, this evolution is not too dissimilar to that in the rest of the OECD. What really differs is the extent of the increase in unemployment and its persistence: the unemployment rate is close to $22 \%$ nowadays, and has been almost $20 \%$ on average for the last decade. ${ }^{2}$

Besides the magnitude of unemployment, the Spanish labour market performance is striking as regards the evolution of both employment and the labour force over the last two decades (see the remaining panels in Fig. 1 which depict employment and participation rates). In 1973, the Spanish employment rate was 5 points lower than the EU and the OECD averages. ${ }^{3}$ Since then, the employment rate has decreased intensively throughout, with the exception of the second half of the $1980 \mathrm{~s}$, and is at present almost 20 points lower than the EU average. This very low employment rate is the joint outcome of a low participation rate (mainly, among women) and a stagnant employment level. Net employment creation has been negative since 1973. Intense job destruction in agriculture (with a share of $30 \%$ at the beginning of the 1970 s and down to less than $10 \%$ at present, after a loss of 2.7 million jobs), partially offset by the expansion of employment in the public sector ( $15 \%$ of employees in the mid-1970s and $25 \%$ nowadays), and a similar job creation performance in the remaining sectors to those in other EU countries, are the main facts behind the poor performance of net job creation in Spain over this period. Furthermore, an overall decline in the participation rate during this period has precluded an even higher rise in unemployment.

Increasing unemployment has been simultaneous with a slow disinflationary process. As shown in Fig. 2, the inflation rate soared to $25 \%$ in 1977, an outcome which is related to the combination of the first oil crisis and the consequences of the end of the Francoist dictatorship which engendered a strong political drive for redistribution and increased the influence of trade unions. Since then, the Spanish

\footnotetext{
${ }^{2}$ An initial reaction to these figures is to take them with disbelief on the grounds of the existence of a large black economy which acts as a 'shock absorber'. Nonetheless, the official unemployment rate is approximately correct: taking account of the underground economy and correcting for some technical problems in the elaboration of the Spanish Labour Force Survey will reduce this rate by 3 points at most (see Toharia, 1995). The fact that unemployment affects mostly second-earners within the family is clearly one of the main reasons behind the lack of a social upheaval and the low job search intensity. So, e.g. the unemployment rate of heads of household is currently about $11 \%$.

${ }^{3}$ The employment rate is defined as the ratio between employment and working age population.
} 


\section{UNEMPLOYMENT RATES}

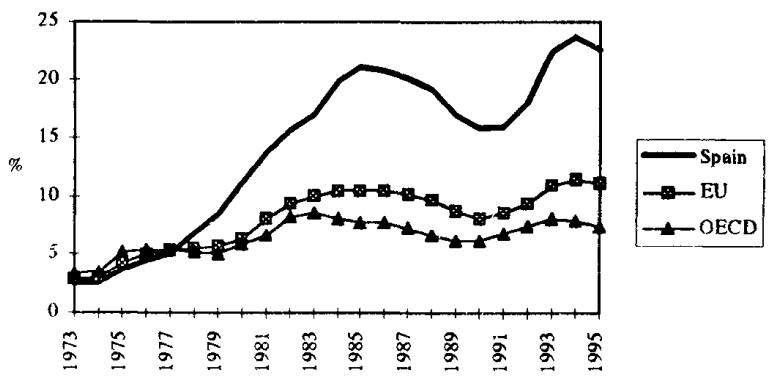

EMPIOYMENT RATES

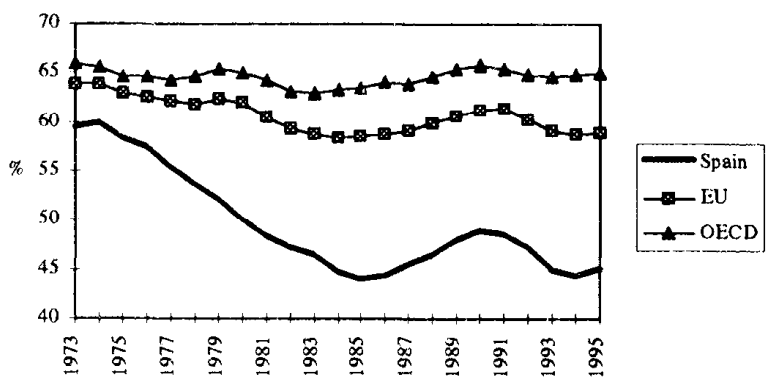

PARTICIPATION RATES

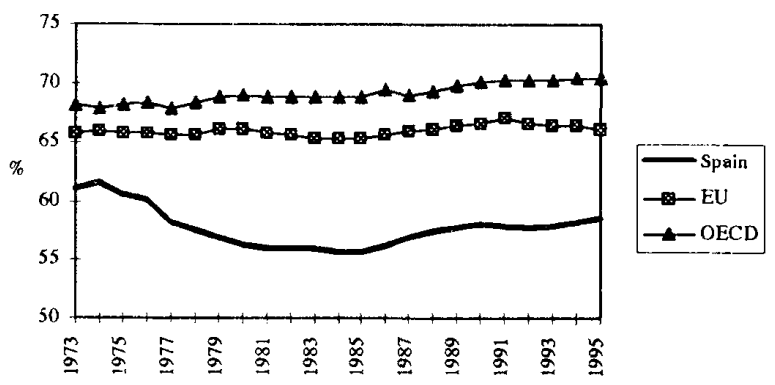

Fig. 1. Unemployment, employment and participation rates.

economy entered a prolonged period of disinflation accompanied by a strikingly large upsurge of unemployment. In fact it has taken almost two decades to produce an almost perfect crossing: the unemployment rate is nowadays close to what the 


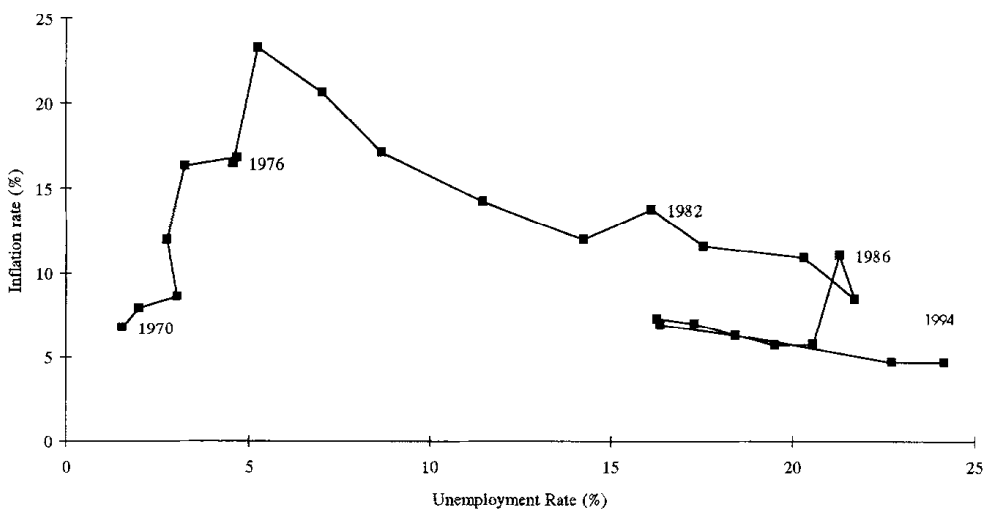

Fig. 2, The Phillips curve.

inflation rate was in 1977 and, conversely, the inflation rate is down to roughly the unemployment rate in the mid-1970s.

In view of the severity of the so-called 'Spanish disease', there has been a large number of studies which have tried to identify the underlying causes of Spanish unemployment. ${ }^{4}$ Although the conclusions that one can draw from these studies differ somewhat, they tend to share two common themes:

- The first theme is about shocks: The standard perception is that Spanish unemployment can only be explained in terms of a combination of shocks. On top of unfavourable starting conditions, stemming from the Francoist autarkic model of development (high protectionism, high share of agriculture, authoritarian and paternalistic labour relations, and a concentration of manufacturing production in energy-intensive sectors), adverse supply shocks in the mid-70s (i.e. oil price hikes, a large temporary increase in labour's share in the advent of democracy) triggered a large initial rise in unemployment. These shocks, combined with a progressive catch-up of labour supply which, as in most Catholic countries, stems from very low female workers' participation rates, plus added-worker effects, and further negative demand shocks during the early 1980 s and the beginning of the 1990 s, have usually been claimed as the sources of the current staggering unemployment rate.

- The second theme is about persistence: This is a story in which the inheritance from the past of high employment protection, the extension of the size and coverage of unemployment benefits, and the rise in labour taxation to finance the unemployment protection system, has led to a high degree of hysteresis and a

\footnotetext{
${ }^{4}$ See, inter alia, Dolado et al. (1986), Bentolila and Blanchard (1989), and Andrés et al. (1990).
} 
slow process of disinflation with correspondingly large sacrifice ratios in terms of unemployment. As an example of this story, consider the diagnosis given in the CEPR report of Blanchard et al. (1995) and in Blanchard and Jimeno (1995). While the CEPR report states that "...the Spanish unemployment rate is extremely persistent even in first differences" (p. 76), the authors of the second paper conclude that "...the evidence in Spain is that of a unit root persistence...We cannot identify the reasons for the increase in unemployment other than hysteretic effects".

In the light of the above conclusions, in this paper we try to shed light on the sources of labour market shocks and on their propagation mechanism in the Spanish economy. To do this we turn to a "Structural Vector Autoregression" (SVAR) approach, which is specially well-suited to breakdown the dynamics of a certain set of variables in the relative contribution of underlying shocks and their transmission effects. ${ }^{5}$ We believe that this approach entails some value added for at least three reasons. First, because earlier empirical evidence on the causes of Spanish unemployment mostly comes from small econometric labour market models (one or two equations), where many of the relevant variables (labour supply and productivity, in particular) are usually treated as exogenous. Since we are interested in identifying the underlying shocks, they should be taken as endogenous. Secondly, because it overcomes some of the difficulties traditionally faced when estimating small quasi-structural econometric models in line with the research summarized in Layard et al. (1991), where measurement problems in the construction of many variables and dubious identification restrictions abound (see Manning, 1993). And, finally, because it allows us to gauge how robust some of the results obtained with the previous approach are, under the comparing SVAR methodology.

Our results confirm the conventional view about the existence of significant shocks and an extreme form of persistence behind the Spanish unemployment dynamics. By imposing full hystercsis in our labour market model, we are able to find a plausible sequence of shocks (price shocks in the late 1970s, wage shocks in the early 1980s, and demand shocks in the early 1990s) with reasonable impulseresponse functions, which helps to explain the evolution of Spanish unemployment over the last two decades. In short, we show that the dismal performance of Spanish unemployment can be explained as the result of a series of adverse shocks, which were difficult to absorb in a context of a rigid system of labour market institutions and disinflationary policies. This finding has relevant policy implications as stressed by the CEPR report of Blanchard et al. (1995), namely, that unless supply side reforms are implemented, deflationary policies will continue to be very costly in unemployment terms.

\footnotetext{
${ }^{5}$ For empirical applications of the SVAR methodology see, inter alia, Blanchard and Quah (1989), Bean (1992), Galí (1992) and Jacobson et al. (1996).
} 
The rest of the paper is structured as follows. In Section 2, we provide a brief overview of the main features of the Spanish labour market and its institutions in order to motivate the main characteristics of the model to be estimated later on. In Section 3, we present the model, which is built upon the assumption of full hysteresis, an extreme assumption whose validity is empirically tested. In Section 4, we estimate a VAR in five variables (output, employment, wage, price and unemployment) with the aim of recovering five structural shocks (aggregate demand, wage-push, price-push, productivity and labour supply shocks) by making use of some long-run identifying restrictions implied by the model. Having identified the shocks, we proceed to quantify their effects through impulse-response functions and forecast error variance decompositions and, in this way, evaluate their relative importance in explaining the nature of the unusually high and persistent Spanish unemployment. Finally, Section 5 briefly concludes.

\section{Facts and explanations}

This section provides a brief description of the most salient features of the Spanish labour market and its institutions over the last two decades. This will help

Table 1

Labour force, employment and unemployment (average annual percentage changes)

\begin{tabular}{lccc}
\hline Period & $1973-85$ & $1986-95$ & $1973-95$ \\
\hline Labour force & $0.34(100)$ & $1.27(100)$ & $0.76(100)$ \\
Total & $-0.14(73)$ & $0.21(68)$ & $0.02(62)$ \\
Male & $1.50(27)$ & $3.24(32)$ & $2.23(38)$ \\
Female & & & \\
Employnient & $-1.25(100)$ & $1.10(100)$ & $-0.18(100)$ \\
Total & $-1.50(73)$ & $0.31(71)$ & $-0.68(65)$ \\
Male & $-0.60(27)$ & $1.27(29)$ & $0.94(35)$ \\
Female & & & $17.8(100)$ \\
Unemployment rate $(\%)$ & $16.5(100)$ & $1.3(100)$ & $13.5(49)$ \\
Total & $14.4(65)$ & $-0.9(60)$ & $24.2(51)$ \\
Male & $20.9(35)$ & $3.2(40)$ & \\
Female & & & $-4.7(10)$ \\
Sectoral employment & $-3.8(25)$ & $-5.8(18)$ & $0.2(73)$ \\
Agriculture & $-1.4(67)$ & $2.2(66)$ & $3.4(17)$ \\
Non-agriculture & $4.5(8)$ & $1.8(16)$ & - \\
Public sector & & & \\
\hline
\end{tabular}

The italic figures represent average annual changes over the relevant period. The figures in parenthesis represent the proportions of male and female labour force, employment and unemployment in 1973 (column 1), 1985 (column 2) and 1995 (column 3). The sectoral employment breakdown is with respect to total employment. Source: Labour Force Survey. 
Table 2

Spanish unemployment: labour market and macroeconomic indicators

\begin{tabular}{|c|c|c|c|c|}
\hline Unemployment rate (\%) & Total & Long-term & Unskilled & Youth \\
\hline Spain & 24.3 & 52.7 & 70.5 & 45.1 \\
\hline Europe & 11.4 & 46.1 & 49.2 & 2.0 \\
\hline 1. Labour costs & $1973-85$ & $1986-95$ & $1973-95$ & \\
\hline Spain & 2.6 & 0.9 & 1.9 & \\
\hline Europe & 1.7 & 1.1 & 1.4 & \\
\hline \multicolumn{5}{|l|}{ 2. Productivity } \\
\hline Spain & 2.8 & 2.3 & 2.6 & \\
\hline Europe & 2.2 & 1.9 & 2.1 & \\
\hline \multicolumn{5}{|l|}{ 3. Real unit labour costs } \\
\hline Spain & -0.2 & -1.4 & -0.7 & \\
\hline Europe & -0.5 & -0.8 & -0.7 & \\
\hline \multicolumn{5}{|l|}{ Monetary policy } \\
\hline 1. Monetary stance & -1.4 & 0.3 & -0.7 & \\
\hline 2. Real interest rate & 1.2 & 5.2 & 2.9 & \\
\hline \multicolumn{5}{|l|}{ Fiscal policy } \\
\hline 1. Fiscal stance & 0.4 & -0.1 & 0.2 & \\
\hline
\end{tabular}

For unskilled, the table gives the proportion of unemployed with low levels of qualification. The monetary stance indicator is defined as the difference between annual money growth (M4) and the money growth target (see ${ }^{11}$ ). A positive sign indicates expansionary monetary policy; the fiscal stance indicator is defined as the change in structural budget deficit. Source: European Economy, 1996.

us to pinpoint several key stylised facts behind Spanish unemployment and to motivate our modelling strategy. For this purpose, Tables 1 and 2 summarise some relevant information on the evolution of employment, unemployment, labour force, labour costs, and a few macroeconomic policy indicators over the last two decades. Considering this descriptive evidence on top of our reading of the relevant literature (see ${ }^{4}$ ), we select the following key stylised facts of the Spanish labour market evolution over that period:

\subsection{Initial conditions}

It is clear that Spain's initial conditions at the beginning of the 1970 s were those of an archaic system of labour relations with a substantially higher share of agricultural employment than that in other EU countries. During the Francoist period, Spain had a rigidly controlled labour market. Trade union activism was prohibited and the social security benefits of the modern welfare state were largely absent. In their place there was a set of rigidly defined working conditions which provided social protection both by making firings difficult and by setting generous severance pay for dismissals. Marimón and Zilibotti (1995) take the initial sectoral composition of the labour force as a crucial explanation of why Spain has created 
less net employment than other EU countries over the last two decades. Their idea is that the shedding of labour out of agriculture into manufacturing and services has taken place at a period when the rate of technological progress was higher than in the past. ${ }^{6}$ Hence, by choosing less labour-intensive techniques, net employment growth has been lower. This argument, no doubt, has an element of truth. However, there are the contrasting cases of Italy and Portugal which also had a large share of agriculture. Particularly relevant is the case of Portugal, a neighbouring economy which shares with Spain similar initial conditions, including the end of a military dictatorship, and has, nonetheless, absorbed the labour force surplus from the rural sector (see Blanchard and Jimeno, 1995). Furthermore, employment in the Spanish public sector by having created 1.1 million jobs since 1972 , ought to have had a countervailing effect on the fall of 2.7 million jobs in agriculture.

\subsection{Wage push}

This is one of the arguments which has been favoured to explain Spain's diversity. However, the evidence is not too strong, at least uniformly, across the sample period. First, although real wages and the 'fiscal wage wedge' have grown substantially since the beginning of the 1970 s, labour productivity growth has more than offset the growth in unit labour costs (see Table 2). It is true that unit labour costs grew above the EU rate during the 1973-85 period, with the government and the employers giving free rein to wage aspirations in the hope of easing the transition from dictatorship to democracy. Nonetheless, it is not less true that they behaved much more moderately since the mid-1980s. However, a new rise in wage growth rates has been observed at the beginning of the 1990s, which, as will be discussed below, can be interpreted in terms of a strengthening of the bargaining power of 'insider' workers in wage setting. This could be due to the segmentation of the labour market in workers with permanent and fixed-term jobs (see Bentolila and Dolado, 1994).

\subsection{Labour supply}

Starting from very low participation rates, the labour force was fairly stable until the beginning of the $1980 \mathrm{~s}$, with a large flow of emigrants towards other European countries helping to keep unemployment rates low until the mid-1970s. Thereafter, as shown in Table 1 , labour force evolution $(0.8 \%$ average annual growth) has been dominated by an increase in female participation in the central

\footnotetext{
${ }^{6}$ For example, the rate of growth of labour saving technical progress in the manufacturing sector went up from $1.2 \%$ per year in the $1960 \mathrm{~s}$ to $2.2 \%$ in the $1970 \mathrm{~s}$, when the job reallocation from agriculture was taking place most intensively (see Andrés et al., 1990).
} 
age groups ( $2.2 \%$ average annual growth). It is from the early 1990 s that labour force growth has decelerated as a result of early retirements, discouraged worker effects and the wider coverage of compulsory education (see Bover and Arellano, 1995). Summing up, there is evidence that its evolution somehow offset that of employment, putting a brake on the fall in unemployment over the expansionary years of the late $1980 \mathrm{~s}$. Apart from that, its role as a direct cause of unemployment seems limited.

\subsection{Unemployment protection system}

Blanchard and Jimeno (1995) argue that some characteristics of the Spanish system may lie behind the very different evolution of unemployment in two economies subject to similar shocks: Portugal and Spain. Whereas before the mid-1980s fewer than $30 \%$ of non-agricultural workers were eligible for unemployment benefits, by 1995 over $60 \%$ were receiving benefits. In contrast, this coverage rate was very low in Portugal throughout the 1980s. However, neither the replacement ratio $(70 \%)$ nor duration are in Spain out of joint with what is available in other EU economies. Notwithstanding, benefits are high enough to make unemployment tolerable, particularly during the first year of joblessness. ${ }^{7}$ Long-term unemployment share is $52 \%$ nowadays, having fallen after the introduction of fixed-term jobs in 1984 and is mainly concentrated on youngsters and women with no work experience who are, therefore, not entitled to unemployment benefits. Thus, reductions of the replacement ratio, as those which took place in 1992 may take a long time to become effective. Nonetheless, the difference between insurance and assistance benefits is weak (see Jimeno and Toharia, 1994).

\subsection{Wage bargaining}

It is often argued that wage rigidity is very high in Spain. However, in terms of the cross-country comparisons of real and nominal wage rigidities carried out by Layard et al. (1991), Spain does not appear to be an outlier on either count. It should be noticed that collective bargaining coordination is not too high, especially among employers, that synchronisation is low, as wage setting is spread throughout the year, and that the system has an inflationary bias in the relationship between tariff wage and wage-drift (see Felgueroso, 1995). Although, in theory, the industrial relations system is characterised by three-tier bargaining at the central, sectoral and firm level. de facto, collective agreements at the industry level are more frequent. They establish wage level floors for subsequent negotiations at the firm level, which then push for additional wage increases. As a result, there is a significant wage drift over negotiated wages established in sectoral

\footnotetext{
${ }^{7}$ See Bover et al. (1996).
} 
collective agreements (see Rodriguez-Palenzuela and Jimeno, 1996). Thus, the Spanish collective bargaining system delivers neither the benefits of centralisation nor those of a decentralised one (see Calmfors and Driffill, 1988). ${ }^{8}$ These arrangements were interrupted by a series of national pacts from 1977 to 1986 which, though ensuring some wage moderation, fostered a narrowing of wage differentials, precisely at a time where labour reallocation was hadly needed. This has had perverse effects on labour mobility which has been much reduced (see Antolín and Bover, 1993). Furthermore, this low factor mobility has been exacerbated by the existence of restrictive rules on work practices and geographical and functional mobility inherited from the old regime, together with a distorting housing price policy.

\subsection{Employment security legislation}

This has been claimed as one of the main obstacles to employment creation. Until the mid-1980s, with the exception of temporary jobs in seasonal activities (like agriculture and tourism), the cmployment relationship was assumcd, by the legislation, to be a permanent one. Workers could only be dismissed under limited conditions, entailing sizeable redundancy payments. Average severance payments grew from just over 4.5 months in 1981 to over 12 months pay by 1993 . Moreover, collective dismissals needed administrative approval by the Labour Ministry and the agreement of worker representatives, and whether individual dismissals are 'fair' or 'unfair' is decided by labour courts. Because of these administrative and labour courts' involvements, dismissals entail large 'red-tape' costs, such as costly bureaucratic procedures, which place an additional financial burden on employers. To avoid those costs, most dismissals cases are settled out of court at amounts above the legal levels. As mentioned above, these rigidities have been somehow compensated for by the introduction in the mid-1980s of fixed-term contracts with low redundancy payments. Since their introduction, this type of contract has been extensively used, representing nowadays over one-third of total employment. So, in this sense, the unions' claim that Spain has a very flexible labour market is only partially correct, since it is also a very segmented market. The effects of such short-tenure contracts on the various dimensions of the labour market have been extensively analyzed, inter alia, by Jimeno and Toharia (1993) and Bentolila and Dolado (1994). They seem to have increased labour turnover, lowered labour and total factor productivity growth and, most importantly, they have enhanced the power of 'insiders' (workers with permanent jobs), leading to unjustified wage rises at the beginning of the $1990 \mathrm{~s}$.

\footnotetext{
${ }^{8}$ Trade union density is low, around $12 \%$, but the coverage of collective bargaining is high, around 70\%. For descriptions of Spanish pay-setting institutions, see Milner and Metcalf (1994) and Jimeno and Toharia (1994).
} 


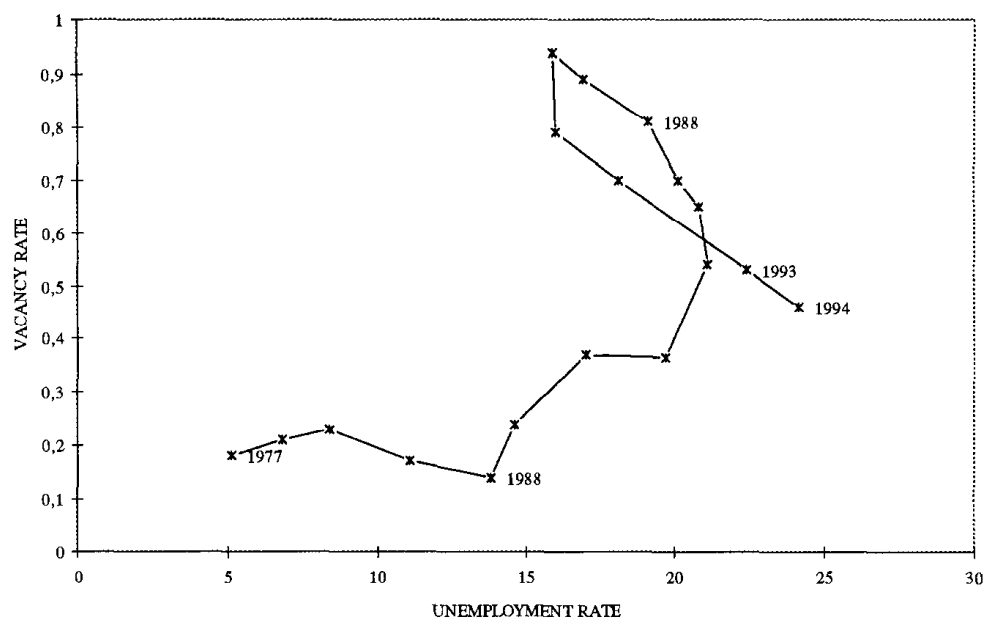

Fig. 3. The unemployment-vacancy curve.

\subsection{Mismatch}

There is general consensus that high, structural unemployment in Europe has been concentrated among unskilled workers, Spain being no exception to this overall trend. In this respect, the working of the collective bargaining system, preventing wage differentials from rising, and the fiscal wedge, which is particularly high in terms of the lower tail of the wage distribution, have contributed to tilt demand away from unskilled labour. At the same time, long-term unemployment, by reducing skills and the will to search for new jobs, has been a major force behind the outward shifts in the UV curve, as reflected in Fig. 3 (see Dolado and Gómez, 1996). In this respect, it is important to notice that Spain is one of the countries where 'active' labour market policies have played a secondary role. Although public expenditure on labour market programmes, as a percentage of GDP, is among the highest in the OECD economies, it is not surprising that the largest share goes to unemployment benefits and so, for example, Spain is one of the European countries which devotes least resources to public employment scrvices. ${ }^{9}$

\footnotetext{
${ }^{9}$ According to OECD (1991), the number of unemployed per staff member in public employment services in 1988 was 712 in Spain, while in Germany, United Kingdom and Sweden it was 86, 53 and 14, respectively.
} 


\subsection{Prices and competition}

Spain has shown all the symptoms of a dual inflation economy, with a tradeable sector highly exposed to international competition and a non-tradeable sector subject to excessive regulation and insufficient competition. The difference between home goods inflation and traded goods inflation has been on average almost $3 \%$ since the mid-1970s. Although, in part, some of this differential may be due to the productivity hypothesis which attributes it to more rapid productivity growth in the traded goods sector, it is also true that the service sector has been protected from competition by legislation, distribution networks and tradition, and by an oversized public sector which in a relatively short period has absorbed labour surplus shed by the other sectors. These rigidities have been particularly tangible in telecommunications and transport which put up the price of many intermediate inputs such as electricity. The real-state and housing rental markets are also highly regulated, inducing severe distortions on labour and capital mobility across regions. ${ }^{10}$ Some of these rigidities have been corrected following Spain's entry into the EC in 1986. However, many still persist, maybe reflecting the lack of confidence of a private sector which has a low propensity to invest in spite of having one of the highest returns on capital in the OECD or the need for voting support from large segments of society which are used to the paternalistic role of the state. Naturally, the permanence of these rigidities has strong effects on the credibility of inflation targets and is one of the main forces behind the slow and painful disinflation process since the mid-1970s.

\subsection{Aggregate demand policies}

As regards fiscal policy, it had a very limited role until the mid-1970s, in the absence of a proper tax system. Later on, after the arrival of democracy and the implementation of a comprehensive tax reform, the direct impact of public intervention on aggregate demand has expanded significantly with the shares of public expenditure and receipt rising from $25 \%$ of GDP at the beginning of the 1970 s to $49 \%$ and $42 \%$ of GDP nowadays, respectively. As can be observed in Table 2, fiscal stance (measured by changes in structural budget deficits) was fairly expansive up to the mid-1980s and slightly restrictive afterwards. Nonetheless, the fiscal policy stance over the second subperiod is dominated by strong fiscal consolidation phases which took place in 1986-87 and 1994-95, with fiscal policy in the remaining years being fairly expansionary. This is particularly true during 1988-91 when, as a result of social unrest due to wage restraints in the first half of the eighties, trade unions successfully pushed for an extension of the social benefit system, giving rise to higher structural deficits which reinforced the strong demand pressures at the time.

\footnotetext{
${ }^{10}$ See also Bentolila and Dolado (1992), Antolín and Bover (1993) and Jimeno and Bentolila (1996).
} 
With regard to monetary policy (measured by deviations of money growth rates from target rates and ex-post real interest rates) ${ }^{11}$, Table 2 shows that it was restrictive during the late 1970 s, up to the mid-1980s, in parallel with the disinflation process which slowed down inflation from $25 \%$ in 1977 to $4.6 \%$ in 1987. As a result of the loose fiscal policy in the late 1980s and the large capital inflows after Spain's entry in the EC, monetary control became more difficult and deviations from target started to arise. The response of the Spanish authorities was to join the EMS in 1989, while the Bank of Spain increased reserve coefficient and established credit controls in 1988 which were lifted in 1991, after demand pressures slowed down. In the absence of supply side reforms, there was a progressive lack of credibility in the government's inflation targets which were offset by higher real interest rates and a progressive overvaluation of the exchange rate aimed at attracting foreign capital inflows (see Revenga, 1993). These flows helped to restore production capacity and gave rise to the 'golden years' of the Spanish economy. Nonetheless, those flows were not as permanent as initially thought and when a demand-led recession was propagated across the EU, following the EMS crisis, investment and employment plummeted and the peseta has been devalued four times since September 1992.

\section{Empirical evidence: A structural VAR approach}

According to the descriptive evidence presented above, Spain has been buffeted by similar shocks to the remainder of Europe since the 1970s. The specificity comes from the permanence of rigidities inherited from the Franco legacy which have given rise to strong persistence mechanisms. Thus, although the analysis of the nature of the shocks is interesting in itself, these shocks alone cannot provide a satisfactory causal explanation of the rise in unemployment by 20 percentage points over two decades, unless there is a propagation mechanism that translates transitory shocks into permanent changes in unemployment. Indeed, in our view, Spanish unemployment is just the result of a series of adverse demand and supply shocks amplified by specific labour market institutions (a combination of the structure of collective bargaining, high firing costs, and barriers to competition in the goods market). Thus, in what follows we will place a strong emphasis on hysteresis to characterise and quantify the importance of various shocks which somehow reflect the various explanations above mentioned.

\footnotetext{
${ }^{11}$ The money target $\left(m^{*}\right)$ has been computed as $\Delta m^{*}=1.6 \Delta \bar{y}+\pi^{*}$ where $\bar{y}$ is (log of) potential output and $\pi^{*}$ is the inflation target. The value 1.6 corresponds to the long-run income elasticity of demand for M4 as estimated by Vega (1994); $\Delta \bar{y}$ is taken as $2.5 \%$ per year, and $\pi^{*}$ is constructed as a $1 \%$ percentage point per year reduction in inflation from 1977 to 1994 . It should also be noted that interest rates were not market determined until the beginning of the $1980 \mathrm{~s}$.
} 


\subsection{A simple macroeconomic model of the Spanish economy}

Our starting point is the simple framework set out in Blanchard and Quah (1989), augmented by specific behavioural relationships which help us in identifying a wide variety of shocks, in a context of hysteresis. In particular, we will be able to identify five types of shocks which, in light of the previous discussion, seem important to us in explaining Spanish unemployment: aggregate demand, wage push, price push, productivity and labour supply shocks.

The model is fairly standard and basically consists of five equations. It contains a minimum of dynamics to simplify the analysis. Yet, its long-run behaviour is consistent with more general dynamic patterns which we consider in the empirical analysis. The first three equations are as follows:

$$
\begin{aligned}
& y=\phi(d-p) \\
& y=n+\theta \\
& p=w-\theta+\mu
\end{aligned}
$$

where $y, p, n, w$ and $(d-p)$ denote the logs of output, price level, employment, nominal wages, and real aggregate demand (reflecting fiscal and monetary policies); in turn, $\theta$ and $\mu$ represent shift factors in productivity and price-setting, respectively, and $d$ is a index of nominal expenditure.

Eq. (1) is a simplified version of an aggregate demand function where $\phi>0$, Eq. (2) is the (long-run) production function under a CRS technology. Finally, Eq. (3) describes the corresponding price setting rule as a mark-up on unit labour cost.

To further characterise the supply side of the labour market, the following three equations are added to the model,

$$
\begin{aligned}
& l=c(w-p)-b u+\tau \\
& w=w^{*}+\varepsilon_{\mathrm{w}}+\gamma_{1} \varepsilon_{\mathrm{d}}+\gamma_{2} \varepsilon_{\mathrm{p}} \\
& w^{*}=\arg \left\{n^{\mathrm{e}}=(1-\lambda) n_{-1}+\lambda l_{-1}\right\}
\end{aligned}
$$

where $l$ is the $\log$ of the labour force, $n^{\mathrm{e}}$ is the expected value of $(\log )$ employment, $u(=l-n)$ is the unemployment rate, $\tau$ is a labour supply shift factor and $\varepsilon_{\mathrm{w}}, \varepsilon_{\mathrm{d}}$ and $\varepsilon_{\mathrm{p}}$ are i.i.d. shocks to wages, demand and prices, respectively, to be defined below.

Eq. (4) is a labour supply function which depends upon real wages $(w-p)$, the unemployment rate $(u)$-capturing a 'discouragement' effect-and other supply shift factors (changes in participation rates, etc.). We expect $c>0$ and $b>0$, the latter reflecting the demoralisation of the long-term unemployed. Eq. (5), in turn, characterises the wage-setting behaviour. Wages have both a backward looking component and a forward-looking one. As in Blanchard and Summers (1986), targeted nominal wages are chosen one period in advance, and are set so as to equate expected employment to a weighted average of lagged labour supply and 
employment. In Eq. $\left(5^{\prime}\right)$ we allow effectively bargained wages to be partially indexed to price and demand surprises through the indexation coefficients $\gamma_{i}$ $(i=1,2)$, so that if $\gamma_{i}=0\left(\gamma_{i}=1\right)$ there is no (complete) indexation. Furthermore, there is an i.i.d. wage shock reflecting changes in union's bargaining power, etc. ${ }^{12}$ As is well known, the microfoundations of Eq. (5) follow typically from an insider-outsider framework (see, e.g. Blanchard and Summers, 1986) which fits well with the characteristic of the Spanish wage-setting process as discussed in Section 2. This parametrisation leads to a partial hysteresis hypothesis when $0<\lambda<1$ and to a full hysteresis one when $\lambda=0$.

To close the model, as customary, we need to specify the stochastic processes governing the evolution of the exogenous shift factors defined earlier. For illustrative purposes, we assume that $d, \theta, \mu$ and $\tau$ evolve as simple random walks

$$
\begin{aligned}
& \Delta d=\varepsilon_{\mathrm{d}} \\
& \Delta \theta=\varepsilon_{\mathrm{s}} \\
& \Delta \mu-\varepsilon_{\mathrm{p}} \\
& \Delta \tau=\varepsilon_{1}
\end{aligned}
$$

where $\varepsilon_{\mathrm{d}}, \varepsilon_{\mathrm{s}}, \varepsilon_{\mathrm{p}}$ and $\varepsilon_{1}$ are i.i.d. uncorrelated aggregate demand, productivity, price and labour supply shocks. However, in the empirical implementation of the model we will allow for richer dynamics and the presence of deterministic trends while maintaining the assumptions in Eqs. (6)-(9).

Solving Eqs. (1)-(9) for unemployment yields

$$
\begin{aligned}
(1-\rho L) u= & (1+b)^{-1}\left\{-\phi\left(1-\gamma_{1}\right) \varepsilon_{\mathrm{d}}+\left[\phi\left(1+\gamma_{2}\right)-c\right] \varepsilon_{\mathrm{p}}\right. \\
& \left.+(1+c-\phi) \varepsilon_{\mathrm{s}}+\varepsilon_{1}+\phi \varepsilon_{\mathrm{w}}\right\}
\end{aligned}
$$

where $L$ is the lag operator and $\rho=(1+b-\lambda) /(1+b)$. Thus, in this partial hysteresis framework, the persistence of unemployment is an increasing function of both the discouragement effect $(b)$ and the influence of lagged employment on wage determination $(\lambda)$. Note that, for finite $b, \rho=1$ is equivalent to $\lambda=0$, so that a full-hysteresis framework is equivalent to unemployment rate being $I(1)$. A formal unit root test does not reject the unit root restriction: for example, an augmented Dickey-Fuller test based on an AR(6) with constant and trend for the sample 1972:1-1994:1, yields a $p$-value on the unit root hypothesis of 0.12 and a $95 \%$ confidence interval for the largest autoregressive root of $(0.97,1.03) .{ }^{13}$ Even

\footnotetext{
${ }^{12}$ We used just $\varepsilon_{\mathrm{p}}$ and $\varepsilon_{\mathrm{d}}$ as subject of indexation, rather than the whole array of shocks, because under alternative identification restrictions which allowed for that possibility, we could not reject that the long-run effects of $\varepsilon_{\mathrm{s}}$ and $\varepsilon_{1}$ on $w$ were zero.

${ }^{13}$ See Stock (1991).
} 
a test of a second unit root, i.e., $u$ is $I(2)$ can only be rejected at the $5 \%$ level. Therefore, we believe that the assumption that $u$ is $I(1)$, or $\lambda=0$, is reasonable, at least as a local approximation for the period and the economy at hand, and we will use it in what follows. ${ }^{14}$

Under full hysteresis, solving out Eqs. (1)-(10), for employment, output, wages, prices and unemployment yields

$$
\begin{aligned}
\Delta n= & \phi\left(1-\gamma_{1}\right) \varepsilon_{\mathrm{d}}+(\phi-1) \varepsilon_{\mathrm{s}}-\phi\left(1+\gamma_{2}\right) \varepsilon_{\mathrm{p}}-\phi \varepsilon_{\mathrm{w}} \\
\Delta y= & \phi\left(1-\gamma_{1}\right) \varepsilon_{\mathrm{d}}+\phi \varepsilon_{\mathrm{s}}-\phi\left(1+\gamma_{2}\right) \varepsilon_{\mathrm{p}}-\phi \varepsilon_{\mathrm{w}} \\
\Delta w= & \gamma_{1} \varepsilon_{\mathrm{d}}+\gamma_{2} \varepsilon_{\mathrm{p}}+\varepsilon_{\mathrm{w}} \\
\Delta p= & \gamma_{1} \varepsilon_{\mathrm{d}}-\varepsilon_{\mathrm{s}}+\left(1+\gamma_{2}\right) \varepsilon_{\mathrm{p}}+\varepsilon_{\mathrm{w}} \\
\Delta u= & (1-b)^{-1}\left\{-\phi\left(1-\gamma_{1}\right) \varepsilon_{\mathrm{d}}+\left[\phi\left(1+\gamma_{2}\right)-c\right] \varepsilon_{\mathrm{p}}\right. \\
& \left.+(1+c-\phi) \varepsilon_{\mathrm{s}}+\varepsilon_{\mathrm{l}}+\phi \varepsilon_{\mathrm{w}}\right\}
\end{aligned}
$$

Thus, aggregate demand shocks $\left(\varepsilon_{\mathrm{d}}\right)$ increase (decrease) employment/output (unemployment) if indexation is not complete. Equally, they increase wages/prices unless there is complete rigidity. Price shocks $\left(\varepsilon_{\mathrm{p}}\right)$ decrease employment/output, increase wages / prices and increase unemployment if the labour supply schedule is relatively inelastic, i.e., $c$ is small. Wage shocks $\left(\varepsilon_{\mathrm{w}}\right)$ decrease employment/output and increase wages/price and unemployment. Productivity shocks $\left(\varepsilon_{\mathrm{s}}\right)$ increase output and employment (the latter if $\phi>1$ ), reduce prices and rise unemployment if $\phi<1$. Note that, under full hysteresis, all shocks have permanent effects on unemployment.

\subsection{A structural VAR approach}

In order to identify the five shocks defined above, we consider the following VAR model, where deterministic trends have been omitted for simplicity

$$
A(L) \Delta X_{\mathrm{t}}=\eta_{\mathrm{t}}
$$

where $X_{\mathrm{t}}$ is a $5 \times 1$ vector of variables including $(y, n, w, p, u)$; $A(L)$ is $k$-th order matrix of polynomials in the lag operator $L$ with all its roots outside the unit circle; and $\eta_{1}$ is a vector of zero-mean i.i.d. innovations with covariance matrix $\Sigma$. The Wold moving average representation of Eq. (16) is given by

$$
\Delta X_{\mathrm{t}}=D(L) \eta_{\mathrm{t}}
$$

where $D(L)=A(L)^{-1}, D_{0}=I$. The innovations are expressed as linear combination of the shocks, i.e., $\eta_{\mathrm{t}}=S \varepsilon_{\mathrm{t}}$, where $S$ is a $(5 \times 5)$ mapping matrix. Assuming

\footnotetext{
${ }^{14}$ See Dolado and López-Salido (1996) for a detailed discussion of the sources of full hysteresis in Spain over a similar sample period.
} 
without loss of generality that the $\varepsilon_{\mathrm{t}}^{\prime} s$ are uncorrelated i.i.d. shocks with unit variances, we get the structural moving-average representation

$$
\Delta X_{\mathrm{t}}=C(L) \varepsilon_{\mathrm{t}}
$$

where $C(L)=D(L) S, C_{\mathrm{o}}=S$. To identify the 25 elements in $S$ we need 10 restrictions, given that the orthonormality of $\varepsilon_{\mathrm{t}}$ imposes 15 restrictions already. These required restrictions can be easily obtained from the structure of $S$ in Eqs. (11)-(15), by exploiting the absence of permanent effects of some shocks on some variables. In fact, the model is overidentified and there are several sets of just-identifying assumptions stemming from the underlying assumptions of the model (CRS in the production function, partial indexation of wages to shocks, ctc.). To select our set of just-identifying assumptions we follow a pragmatic approach: we estimate the model under a given set of identifying assumptions and obtain the impulse-response functions; if the impulse-response functions are not reasonable or fail the overidentifying restrictions we try a different set of identifying assumptions. This procedure leads us to choose a set of identifying restrictions consisting of nine long-run restrictions, all of which can be easily derived from the structure of the model in Eqs. (11)-(15), and one contemporaneous restriction. The long-run restrictions are the following: $\varepsilon_{\mathrm{d}}$ has no permanent effect on productivity $(y-n)$ and real wages $(w-p)$, since, by CRS, only productivity shocks increase productivity in the long-run, while the permanent component of real wages is only driven by productivity and price push shocks; $\varepsilon_{\mathrm{s}}$ has no permanent effect on the wage share, as productivity shocks increase productivity and real wages by the same amount; $\varepsilon_{\mathrm{w}}$ has no permanent effect on productivity and real wages, for the same reasons explained with regard to $\varepsilon_{\mathrm{d}}$; and $\varepsilon_{1}$ does not affect $y, n, w$ and $p$ in the long-run, since outsiders do not affect the wage determination process. The short-run restriction is the conventional one that $\varepsilon_{\mathrm{d}}$ does not affect nominal wages within the initial quarter, which allows us to distinguish $\varepsilon_{\mathrm{d}}$ from $\varepsilon_{\mathrm{w}}$.

\section{Results}

\subsection{Data and VAR estimation}

All the data are drawn from the Quarterly National Account and the Statistical Bulletin of the Bank of Spain and correspond to non-seasonally adjusted form. The variables used to estimate the VAR in Eq. (16) are GDP in 1986 prices $(y)$, total employment $(n)$, average monthly labour costs $(w)$, GDP deflator $(p)$ and the total unemployment rate $(u)$. The VAR was estimated using quarterly data from 1971:1 to 1994:1. The optimal lag length was derived using the AIC and BIC criteria, leading to a choice of four lags for each series. All the variables appeared to be $I(1)$, with the exception of the wage and price levels which were borderline 
$I(1) / I(2)$. Deterministic seasonality was accounted for by the use of seasonal dummies, while the evidence on the $I(2)$ character of wage and price levels disappeared once a breaking trend in 1978:1 was removed from price and wage inflation rates. ${ }^{15}$ Given this evidence, and the fact that the procedure of Johansen (1988) did not indicate signs of cointegration among the variables, the VAR was specified in first differenced form, in agreement with the model in the previous section. The estimated VAR coefficients are not reported here for the sake of brevity, but there were no signs of misspecification in any of the equations. Instead, the next section considers the impulse response (IR) functions and the forecast error variance (FV) decompositions embedded within the VAR. Finally, we also tested for subsample stability by estimating the model before and after 1980. Subsample stability tests could not reject the hypothesis that the coefficients of the VAR were identical in the two samples (1971:1 to 1979:4 and 1980:1 to 1994:1), although there were some signs of lack of stability in the price equation. ${ }^{16}$ However, the IR functions and the results of the shock accounting exercise presented below are not qualitatively different when the model is estimated with the restrictive sample (1980:1 to 1994:1). ${ }^{17}$ Hence, in what follows, we will report the results obtained with the whole sample (1971:1 to 1994:1).

\subsection{Impulse-response functions and variance decompositions}

Fig. 4 plots the IR function of output, employment, real wages and unemployment with respect to an innovation in each of the shocks equivalent to a $1 \%$ point rise. In the top panel we get the dynamic pattern to an $\varepsilon_{\mathrm{d}}$ shock: employment and output rise with no effect on productivity after 10 years; real wages are only marginally affected in the short run and unemployment falls by less that the increase in output/employment, as predicted by Eq. (15), which implies a positive value of the discouragement coefficient effect $(b)$ of about 0.5 . In the second panel, the dynamic effects of an $\varepsilon_{\mathrm{w}}$ shock are depicted: they decrease unemployment and only increase real wages in the short-run. In the third panel, we get the effects of an $\varepsilon_{\mathrm{p}}$ shock: they decrease employment and output while they reduce real wages and increase unemployment which, in turn, implies that $\phi\left(1+\gamma_{2}\right)>c$, i.e., labour supply is not too elastic. In the fourth panel, the effects of an $\varepsilon_{\mathrm{s}}$ shock appear, which leaves the wage share unaffected and tends to increase unemploy-

\footnotetext{
${ }^{15}$ Indeed, using the testing procedure of Perron (1989) we could reject the null hypothesis that $w$ and $p$ were $I(2)$ against the alternative hypothesis that they were $I(1)$ with the trend described above.

${ }^{16}$ Chow's tests are 105.96 ( $p$-value 0.32 ) for the whole VAR, and 11.87 ( $p$-value.53), 27.93 ( $p$-value.11), 16.11 ( $p$-value.71), 40.45 ( $p$-value.01), and 17.68 ( $p$-value.61) for the output equation, employment equation, the wage equation, the price equation, and the unemployment equation, respectively.

${ }^{17}$ These impulse-response functions and shock-accounting results from the restricted sample are available from the authors upon request.
} 
(a)

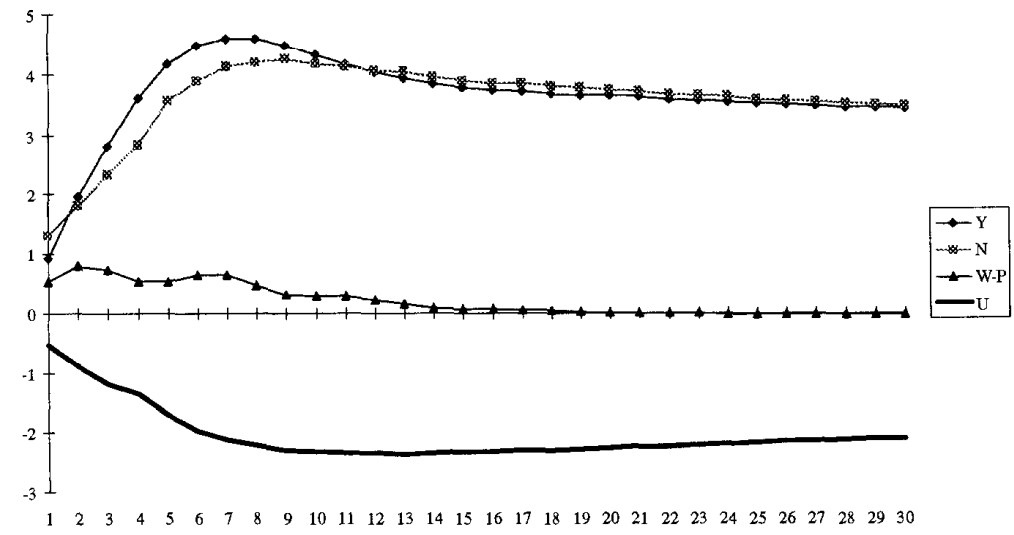

(b) RESPONSES TO A WAGE-PUSH SHOCK

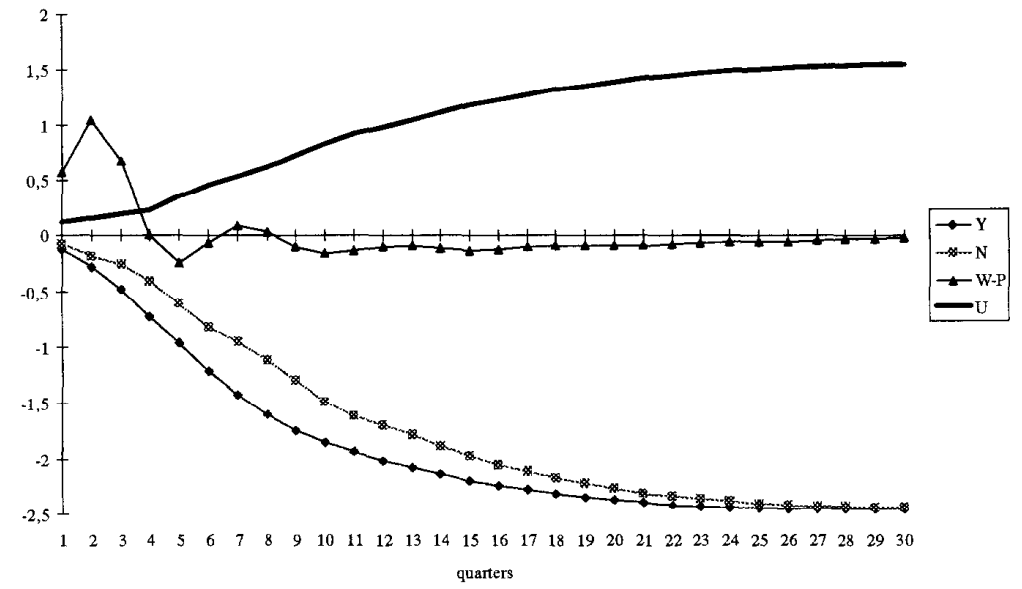

Fig. 4. Inpulse-response functions.

ment in the short run. Finally, in the bottom panel, by assumption in the identifying procedure, $\varepsilon_{1}$ has only permanent effects on unemployment while real wages, after an initial decline, show a slowly mean-reverting process.

As regards the FV decompositions, shown in Table 3, we find evidence that aggregate demand shocks dominate the variability of output at all horizons and, to a lesser extent the same feature is shared by employment, although in this case 
(c)

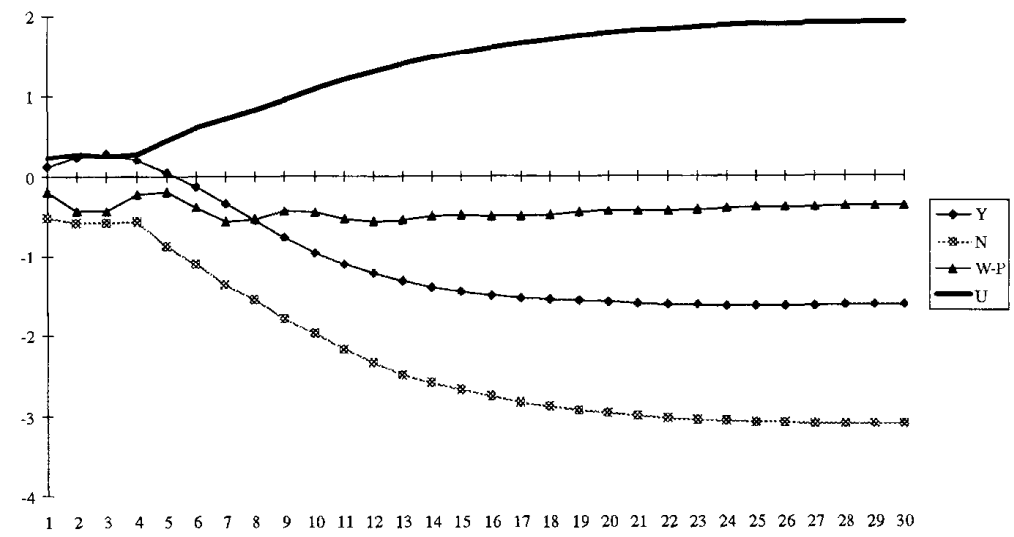

(d) RESPONSES TO A PRODUCTIVTY SHOCK

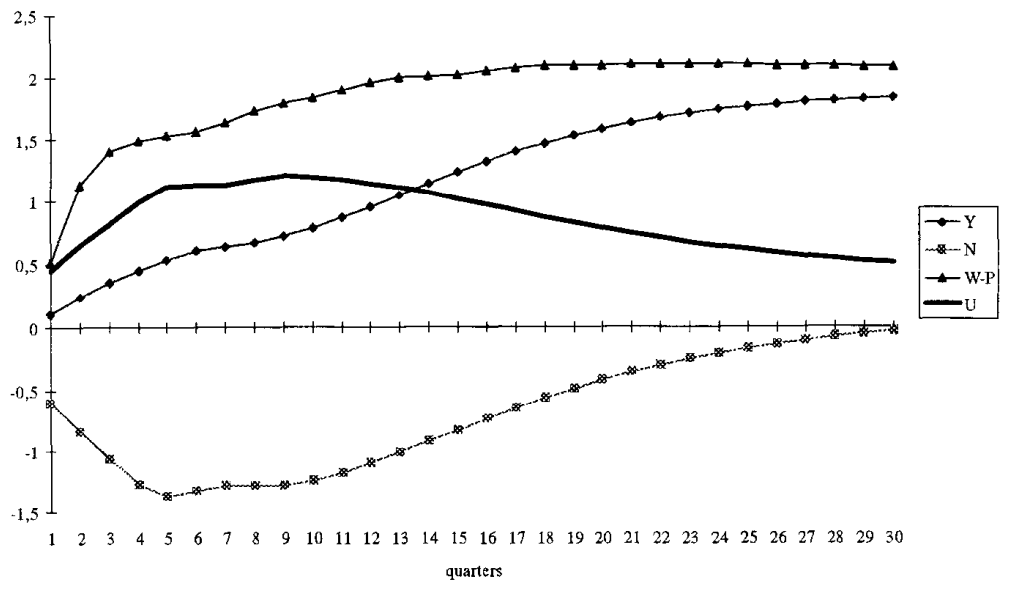

Fig. 4 (continued).

price and productivity shocks also play a role. The variability of wages is basically explained by its own shocks whilst that of prices seems to be dominated by wage, price and productivity shocks. Lastly, and most importantly, the short-run variability of the unemployment rate is mainly explained by productivity and labour supply shocks, whereas in the long-run the contributions of the different shocks do not differ by much. The latter result seems to provide some favourable evidence 
(e)

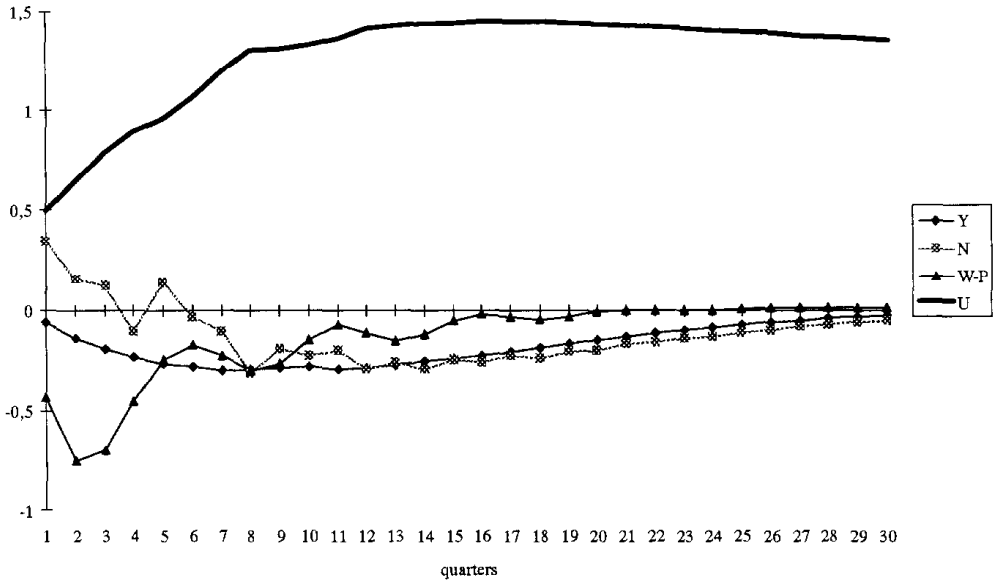

Fig. 4 (continued).

Table 3

Forecast error variance decomposition

\begin{tabular}{lcrrrl}
\hline Period/shock & Demand & Wage & Price & Productivity & Labour supply \\
\hline Output & & & & & \\
1 & 83.6 & 6.3 & 6.3 & 3.1 & 0.7 \\
4 & 78.0 & 14.1 & 3.3 & 4.1 & 0.4 \\
$\infty$ & 52.0 & 23.2 & 7.9 & 16.4 & 0.4 \\
Employment & & & & & \\
1 & 40.3 & 0.7 & 25.9 & 28.4 & 4.7 \\
4 & 42.7 & 3.4 & 19.1 & 24.2 & 6.4 \\
$\infty$ & 31.5 & 13.1 & 29.5 & 19.6 & 6.3 \\
Wages & & & & & \\
1 & 0.1 & 91.6 & 6.7 & 1.2 & 0.4 \\
4 & 0.3 & 81.8 & 11.7 & 3.7 & 2.6 \\
$\infty$ & 3.1 & 74.9 & 13.6 & 5.7 & 2.6 \\
Prices & & & & & \\
1 & 8.8 & 17.4 & 27.1 & 40.8 & 6.0 \\
4 & 4.9 & 20.5 & 20.1 & 50.2 & 4.3 \\
$\infty$ & 6.9 & 21.8 & 20.2 & 46.6 & 4.5 \\
Unemployment rate & & & & & \\
1 & 19.6 & 3.9 & 14.7 & 36.7 & 25.1 \\
4 & 25.4 & 3.4 & 11.1 & 36.6 & 25.4 \\
$\infty$ & 22.5 & 13.0 & 23.0 & 25.5 & 16.0 \\
\hline
\end{tabular}


for our conjecture that no single shock plays an influential role in explaining Spanish unemployment. Rather, it results from a series of adverse supply shocks, compounded by disinflationary policies and a system of labour market institutions which have exacerbated the hysteretic mechanism in the propagation of those shocks.

\subsection{Interpreting the results}

To extend the interpretation of the rise in unemployment, Fig. 5 shows the accumulated effects of each of the above identified shocks, in terms of percentage points of unemployment, for four significant sub-samples with the sample period. Bars above the zero line plot unemployment increases whilst those below the zero line depict reductions. ${ }^{18}$

The results match satisfactorily most of the discussion in Section 2. Over the second half of the 1970s there is a large price shock following the delayed effects of the first oil crisis in the Spanish economy which was partly accommodated by monetary policy, paving the way for price rises. At the same time, income policy agreements, which were signed during the 1978-86 period, reduced the negative effects of the wage shocks in that period. During the first half of the 1980s, monetary policy was tighter while fiscal policy became more expansive, setting the basis of the welfare state, implying a joint neutral effect of aggregate demand shocks on unemployment. Price shocks became negative as a reflection of the progressive opening of the Spanish economy, while wage shocks became the most important source of unemployment, mainly because of the rise in non-wage labour costs. ${ }^{19}$ Over the second half of the 1980s, the so called 'golden years', fiscal policy continued being expansionary, except for 1986 and 1987, overcoming the tightness of monetary policy. Equally, price margins, adjusting to the increase in foreign competition following Spain's entry in EC, behaved very favourably giving rise to the largest reduction of unemployment over the sample period. Finally, during the first half of the 1990 s, both a very negative demand shock and a wage shock occurred. The former was mainly due to restrictive monetary policy, reflecting the turbulence in the ERM after Germany's reunification. The latter, in turn, probably reflected the strengthening of the insider effects following the wide use of fixed-term contracts and some redistributive effects by unions to restore the wage share. As regards productivity and labour supply shocks, the former seem to have been more important, particularly in the second halves of the 1970s and

\footnotetext{
${ }^{18}$ Given that all shocks have potentially permanent effects on unemployment, the unemployment rate in each sub-period is the outcome of the shocks during the period and the projection from the past. Fig. 5 only depicts the shocks.

${ }^{19}$ See Dolado et al. (1986).
} 


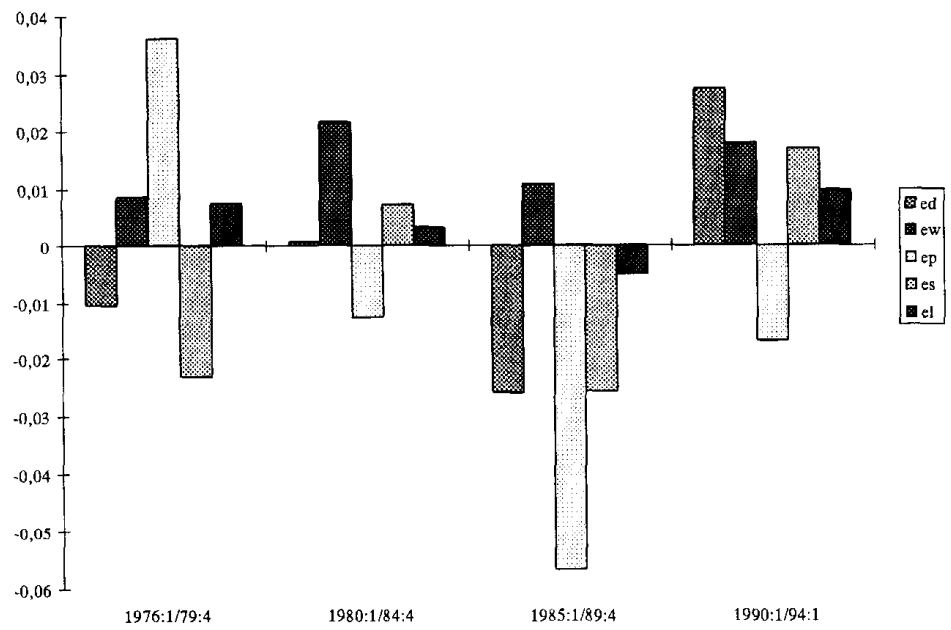

Fig. 5. Accumulated structural shocks.

1980s where labour productivity slowdowns decreased unemployment in the short run. On the other hand, labour supply shocks seem to have played a minor role, in accordance with our discussion of labour supply in Section 2.

In sum, the permanence of rigidities in both good and labour markets has implied an extreme degree of persistence in the propagation on shocks. The relative contribution of each type of shock has been different in the four relevant sub-periods during the sample. Furthermore, the existence of strong hysteresis has had serious consequences on the sluggishness of the disinflation process. This is so since if we compare such an economy to one without hysteretic features, the presence of hysteresis makes it easier to raise unemployment and harder to reduce it, particularly if those rigidities lower the credibility of ambitious inflation targets (see Appendix A).

\section{Conclusions}

In this paper we have estimated a small vector autoregressive model of the Spanish economy in order to quantify the contribution of several potential factors which might have explained the staggering rise in unemployment over the last two decades. We have identified five types of structural shocks and associated them to various arguments which have been put forward to explain Spanish unemployment. Our results suggest that Spanish unemployment results from a series of 
adverse shocks, compounded by disinflationary policies and a system of labour market institutions and product market rigidities which convert transitory shocks into permanent ones. In particular, we find that price and wage shocks dominated the second half of the 1970s and the first half of the 1980s, periods in which unemployment rose by 3 and 9 points, respectively. In turn, the recession of the early 1990s is the outcome of negative demand shocks and, to a lesser extent, of wage and productivity shocks. On the other hand, the boom in the second half of the 1980s is dominated by favourable demand and price shocks at a time where expansionary policy was accompanied by structural reforms. Nonetheless, the permanence of many hysteretic features prevented unemployment from falling below the $16 \%$ mark.

Our shock accounting exercise is somehow consistent with the following political economy interpretation of the course of events. Many inefficiencies inherited from the old autocratic system were bound to be reformed, but unfortunately the political reform coincided with the two oil price shocks. To offset the initial rise in unemployment, a neo-corporatist arrangement (social pacts) was tried. These arrangements generally operated in favour of capital and the otherwise unemployed, and against the interests of the employed (particularly skilled workers). In order to ensure the unions' participation in the agreement, the government provided much more generous welfare benefits and maintained employment protection from the past. This led to an increasing divergence between the employed and the unemployed, with the state inheriting an irreversible increase in social security outlays. In these circumstances, adverse shocks to the economy triggered undesirable adjustments. Employment destruction took place in big chunks. In addition, more inactive people meant less tax revenue, more benefits to be paid and, consequently, higher tax rates and non-wage costs. This caused further inactivity and an increase in the fiscal wedge, thereby lessening the incentive to create jobs. At the same time disinflation has been very slow, in spite of several aggressive attempts to reduce inflation. This is so because, unless the mechanisms leading to persistence are corrected, a small rise in unemployment today has large adverse effects on unemployment in subsequent periods.

What are the normative conclusions for the future? The fact that Spain has the highest and most stubborn unemployment rate in the OECD means that the 'Spanish disease' is unique and therefore needs specific remedies. In this respect, the recent CEPR report on Spanish unemployment by Blanchard et al. (1995) argues that this is the right moment to call for a social pact, without the constraints of the past. Redistributive policies in favour of capital are no longer needed, as reflected by the fall of the wage share from $78 \%$ in 1975 to $66 \%$ nowadays, and a 'two-handed' approach seems feasible which would entail lowering firing costs, eliminating quasi-monopoly rents in many product markets and implementing a more expansionary demand (see, also, Bean, 1994). Likewise, an intensification of efficient active labour market policies targeted on long-term unemployment is badly needed. Otherwise, history will repeat itself. 


\section{Appendix A}

To analyse the effects of hysteresis on inflation, we use a slightly different version of the model in the main text. The model consists of four equations: a Phillips curve, an aggregate demand, an aggregate supply and a policy rule equation. The Phillips curve, which can be obtained by combining Eqs. (3) and (5) in the main text, allowing for nominal rigidities in terms of price surprises, is an expectations augmented one such that,

$$
\pi=\pi^{\mathrm{e}}-\beta\left[u-(1-\lambda) u_{-1}\right]+x
$$

where $\pi=$ inflation, $\pi^{\mathrm{e}}=$ expected inflation, $u=$ unemployment rate, $x=$ shift factors. As in the model in Section 3, $\lambda$ denotes the degree of hysteresis, so that $\lambda=0$ implies full hysteresis. The aggregate demand equation, as in Eq. (1) in the text with $\phi=1$, is simply written as

$$
y=m-p
$$

where $y=(\log$ of $)$ output, $m=(\log$ of $)$ money stock and $p=(\log$ of $)$ price level. Note that $\pi=p-p_{-1}=\Delta p$. Letting $\bar{y}(t)$ represent the log of potential output which, for simplicity, is assumed to be a linear trend, the underlying production function (assuming CRS as in Eq. (2) in the text) implies

$$
y-\bar{y}=u
$$

Lastly the policy rule is slightly morc complicatcd than Eq. (6) and is written as

$$
\Delta m-\pi=-\gamma\left(\pi-\pi^{*}\right)
$$

where $\pi^{*}=$ government's inflation target. The parameter $\gamma$ represents the degree of accommodation of monetary policy, i.e., $\gamma=0$ implies fully accommodating policy whilst $\gamma=1$ implies no accommodation, namely $\Delta m=\pi^{*}$.

Solving the three equations in terms of $u$ and $\pi$ yields

$$
\begin{aligned}
& u=c_{1} u_{-1}+c_{2}\left(x+\pi^{\mathrm{e}}-\pi^{*}\right) \\
& \pi-\pi^{*}=-d_{1} u_{-1}+d_{2}\left(x+\pi^{\mathrm{e}}-\pi^{*}\right)
\end{aligned}
$$

where $c_{1}=1-(\lambda \beta \gamma) /(1+\beta \gamma), d_{1}=(\beta \lambda) /(1+\beta \gamma), c_{2}=(\gamma) /(1+\beta \gamma)$, and $d_{2}=\left(c_{2}\right) /(\gamma)$.

The variable $\left(\pi^{\mathrm{e}}-\pi^{*}\right)$ represents the deviation of expected inflation from target inflation and can be interpreted as an index of lack of credibility, namely, the more credible are inflation targets, the closer will be the market's expectations to them. From Eqs. (A.5) and (A.6), it follows that the lower is $\lambda$ (increasing hysteresis) the lower is the effect of lagged unemployment on inflation, for a given inflation target, and the higher the persistence of unemployment. Finally, the lower is credibility the larger will be inflation and unemployment for given past unemployment and inflation target. 


\section{References}

Andrés, J., Dolado, J., Molinas, C., Sebastián, M., Zabalza, A., 1990. The influence of demand and capital constraints on Spanish unemployment. In: Dreze, J., Bean, C. (Eds.), Europe's Employment Problem. MIT Press, ch. 10.

Antolín, P., Bover, O., 1993. Regional Migration in Spain: The Effects of Personal Characteristics and of Unemployment, Wage and House Price Differentials Using Pooled Cross-Sections. Bank of Spain, Working Paper 9318.

Bean, C., 1992. Identifying the Causes of British Unemployment. CEP/LSE Working Paper 276.

Bean, C., 1994. The Role of Demand Management Policies in Reducing Unemployment. CEP/LSE Discussion Paper 222.

Bentolita, S., Blanchard, O., 1989. Spanish unemployment. Economic Policy 10, 233-281.

Bentolila, S., Dolado, J., 1992. Mismatch and internal migration in Spain, 1962-86. In: Padoa-Schiopa, F. (Ed.), Mismatch and Labour Mobility. Cambridge University Press, ch. 5.

Bentolila, S., Dolado, J., 1994. Labour flexibility and wages: Lessons from Spain. Economic Policy 18 , 55-99.

Blanchard, O., Jimeno, J., 1995. Structural unemployment: Spain versus Portugal. American Economic Review 85, 212-218.

Blanchard, O., Jimeno, J., Andrés, J., Bean, C., Malinvaud, E., Revenga, A., Saint-Paul, G., Snower, D., Solow, R., Taguas, D., Toharia, L., 1995. Spanish Unemployment: Is There a Solution? CEPR London.

Blanchard, O., Quah, D., 1989. The dynamic effects of aggregate demand and supply disturbances. American Economic Review, 655-673.

Blanchard, O., Summers, L., 1986. Hystcresis and the European unemployment problem. NBER Macroeconomics Annual 1986, 15-78.

Bover, O., Arellano, M., 1995. Female labour force participation in the 1980s: The case of Spain. Investigaciones Económicas 19, 171-194.

Bover, O., Arellano, M., Bentolila, S., 1996. Unemployment duration, benefit duration, and the business cycle Bank of Spain. Mimeo.

Calmfors, L., Driffill, J., 1988. Bargaining structure, corporatism and macroeconomic performance. Economic Policy 6, 13-61.

Dolado, J., Gómez, R., 1996. La Relación entre Vacantes y Desempleo en España: Perturbaciones Agregadas y de Reasignación Bank of Spain. Mimeo.

Dolado, J., López-Salido, D., 1996. Supply-Side Shocks and Hysteresis: An Empirical Analysis of the Spanish Labour Market. CEPR Discussion Paper 1334.

Dolado, J., Malo de Molina, J.L., Zabalza, A., 1986. Spanish industrial unemployment: Some explanatory factors. Economica 53, 313-334.

European Economy, Report and Studies, 1996, European Commission, Directorate General for Economic and Financial Affairs, Brussels.

Felgueroso, F., 1995. Industrywide collective bargaining, wage gains and black labour market in Spain. Universidad de Oviedo. Mimeo.

Galí, J., 1992. How well does the IS-LM model fit postwar, U.S. data?. Quarterly Journal of Economics 107, 709-738.

Jacobson, T., Vredin, A., Warne, A., 1996. Common Trends and Hysteresis in Scandinavian Unemployment. European Economic Review, forthcoming.

Jimeno, J., Bentolila, S., 1996. Regional Unemployment Persistence (Spain 1976-94). Labour Economics, forthcoming.

Jimeno, J., Toharia, L., 1993. The effects of fixed-term employment on wages: Theory and evidence from Spain. Investigaciones Económicas 17, 475-494.

Jimeno, J., Toharia, L., 1994. Unemployment and labour market flexibility: Spain, international labour office. 
Johansen, S., 1988. Statistical analysis of cointegrating vectors. Journal of Economic Dynamics and Control 12, 231-254.

Labour Force Survey (Encuesta de Población Activa), Instituto Nacional de Estadística, Madrid, several issues.

Layard, R., Nickell, S., Jackman, R., 1991. Unemployment. Oxford University Press.

Manning, A., 1993. Wage bargaining and the Phillips curve: The identification and specification of the wage equation. Economic Journal 103, 98-118.

Marimón, R., Zilibotti, F., 1995. Actual vs. Virtual Employment in Europe: Why is there Less Employment in Spain? Universitat Pompeu Fabra. Mimeo.

Milner, S., Metcalf, D., 1994. Spanish Pay Setting Institutions and Performance Outcomes. CEP Discussion Paper No. 198.

OECD, 1991. Employment Outlook. Paris.

Perron, P., 1989. The great crash, the oil shock and the unit root hypothesis. Econometrica 57 , $1.361-1402$.

Revenga, A., 1993. Credibility and Inflation Persistence in the EMS Bank of Spain. Working Paper 9321.

Rodriguez-Palenzuela, D., Jimeno, J.F., 1996. Wage drift in collective bargaining at the firm level: Evidence from Spain. Annales d'Économie et de Statistique 41-42, 187-206.

Stock, J., 1991. Confidence intervals of the largest autoregressive root in U.S. macroeconomic time series. Journal of Monetary Economies 28, 435-460.

Toharia, L., 1995. Unemployment in Spain: How can it be so high? Universidad de Alcalá de Henares. Mimeo.

Vega, J.L., 1994. Is There a Stable Long-Run Demand for ALP? Banco de España. Discussion Paper No. 9422 . 